\title{
Analysis on Financing Mode of Characteristic Town of Guizhou Minority Area_- Taking the Xiasi Town as an Example
}

\author{
Yongjin Liu Ruo Shi \\ School of Finance, Guizhou University of Finance and Economics, Guiyang Guizhou \\ 550025, China
}

\begin{abstract}
We should make full use of the advantages of Guizhou minority areas, such as culture and ecological resources, and promote the economic development of minority areas through the construction of Characteristic Towns in minority areas, so we can realize the strategic goal of poverty alleviation in ethnic minority areas in Guizhou Province. Financial support is the cornerstone of the development of characteristic towns. It is of great significance to choose the financing mode suited to the ethnic areas and towns for promoting the development and construction of Characteristic Towns. Based on the investigation into the present town, the advantages of PPP financing mode in minority areas and problems in the construction of town features are discussed in this paper, so as to provide some enlightenment and experience for the financial support for the construction of the characteristics of ethnic minority areas of town.
\end{abstract}

\section{Keywords}

Characteristic town; Financing model; PPP Franchise

\section{贵州民族地区特色小镇融资模式探析 \\ 一以下司古镇为例}

刘永进 施若

贵州财经大学金融学院, 贵阳 550025, 中国

摘要：充分利用贵州少数民族地区文化、生态资源等优势，通过民族地区特色小镇建设，拉 动少数民族地区经济发展，以实现贵州省少数民族地区脱贫的战略目标。金融支持是特色小 镇发展的基石，选择与民族地区城镇向适应的融资模式对于促进特色小镇发展建设具有重要 的意义。论文在对下司古镇的调研分析的基础上，探讨 PPP 融资模式在民族地区的特色小 镇建设中存在的优势及问题，为民族地区特色小镇的建设金融支持提供一定的启迪和经验。

关键词：民族地区；特色小镇；融资模式；PPP 特许经营 


\section{1.特色小镇背景及内涵}

何为特色小镇? 早在百年前, 外 国就已有特色小镇出现, 如美国的格 林威治、英国的剑桥等都是世界闻名 的小镇。总结其特点, 可定义为: 依 赖某一特色产业以及特色环境, 打造 的具有明确产业定位、文化内涵、旅 游特征和一定社区功能的综合开发项 目，是旅游景区、消费产业聚集区、 新型城镇化发展区三区合一，产城一 体化的新型城镇化模式。2014 年 10 月 浙江省省长李强第一次公开提出 “特 色小镇” 的概念, 随后特色小镇项目 迅速在全国范围内建设。2016 年 3 月

《国家 “十三五”规划纲要》提出 “因地制宜发展特色鲜明、产城融 合、充满鬼米力的小城镇”。7 月, 住房 城乡建设部、国家发展改革委、财政 部联合下发《关于开展特色小镇培育 工作的通知》, 提出到 2020 年培育 1000 个左右各具特色、富有活力的休 闲旅游、传统文化、美丽宜居等特色 小镇,引领带动全国小城镇建设。各省 也相继出台了各自特色小镇的建设规 划和目标。早在 2012 年, 贵州就开始 发展建设小城镇, 贵州省在当年出台 《关于加快推进小城镇建设的意 见》, 首次提出到 2015 年建设 100 个 各具特色的示范小城镇, 而到 2017 年 要成功实现新增城镇人口 120 万, 城 镇化水平提升到 $45 \%$ 左右。2015 年, 贵州省住建部门总结其三年建设 100 个示范小城镇的经验, 发布《关于打 造贵州省小城镇升级版的实施意 见》，表示将持续支持小城镇的开发 建设。

\section{2.贵州发展民族特色小镇助推城镇化}

2016 年, 我国城镇常住人口 7.92 亿, 城镇化率为 $57.35 \%$, 社会结构变
化较大, 逐步从“乡村中国” 迈入 “城市中国”。但是，贵州省 2016年 统计的城镇化率仅 $42 \%$, 远低于国内 总体水平，被称为 “城市中国” 中的 “乡村贵州”。贵州有 56 个名族聚 居, 全省 88 个县均匀少数民族分部。 少数民族人口占全省 $36 \%$ ，其中有 18 个民族占比较多, 如苗族、布依族、 侗族等。全省有 3 个民族自治州、11 个民族自治县， 253 个民族乡，少数民 族自治地占地面积约 9.78 万平方公 里, 超过贵州全省总面积的一半。长 久以来，众多民族混居，各民族和平 共处，共同制造了美丽灿烂的贵州文 化, 以建设特色小镇为契机, 将促进 贵州旅游经济更快更好发展。因此从 2012 年开始, 贵州紧密结合其地理文 化以及资源, 突出产业、自然、历 史、文化和民族特色, 在小城镇建设 方面具有独到之处。

2015 年贵州省委省政府提出建设 100 个示范小城镇的战略, 取得了一定 成效, 城镇人口增加十万, 新增加近 8 万就业岗位, 开发建造了一批旅游小 镇、白酒小镇、茶叶小镇等风格不同 特色小镇。贵州在 2016 年 10 月住房 城乡建设部公布的 127 个示范特色小 镇中, 今年 8 月公布的第二批又有 10 个入选，贵阳市花溪区青岩镇、六盘 水市六枝特区郎岱镇、遵义市仁怀市 茅台镇、安顺市西秀区旧州镇、黔东 南州雷山县西江镇, 依托旅游产业, 同时引进企业共同发展当地经济。 2017 年春节期间, 贵州总共接待游客 1984.57 万人次, 旅游收入超过 85 亿 元, 相比去年与春节假期分别增长 $28 \%$ 和 32\% , 贵州旅游发展持续呈现 “井喷”态势, 发展旅游特色小镇产 业成效渐显。

\section{3.下司古镇特色小镇建设金融支持现状 分析}


下司古镇贵州著名旅游景区，正 在申报 4A 级景区。下司古镇地理位置 优越, 地处凯里西南部, 在清水江 上。全镇占地 154 平方千米, 其中耕 地面积有 2.21 万亩; 总人口大约 5 万 人, 其中苗族、伀佬族人口占比较 高。下司古镇有 “小上海”、“清水 江上的明珠”之美称, 同时是世界名 犬下司犬之乡。另外, 这里遍布人文 历史遗迹, 如桃园岛、月亮岛等, 都 是热门的旅游景点; “酸汤鱼” 、

“草烧狗” 是下司名菜, 吸引了一批 又一批的游客前来。下司古镇是 2013 年贵州省提出重点建设的 100 个旅游 景区之一；2016年 3 月，贵州省出台

《省民宗委关于加强民族特色小镇保 护与发展工作的指导意见》, 下司古 镇完全满足该意见的要求, 是一处具 有丰富旅游价值的民族特色小镇。

2012 年底, 凯里经济开发区开始 规划下司古镇维修改造项目, 尤其是 在古镇房屋及基础设施方面进行升级 改造。在 2013-2014 年, 以陈可实教 授 6 平方公里的规划来开发建设, 古 镇内修旧如旧, 恢复建设明清、民国 时期的各类场馆, 后因两县市资产盘 点, 权属交接搁置两年。2016 年 7 月, 清江旅游开发有限公司成立, 它 是由贵州凯里经济开发区国有资产管 理办公室全额出资，其注册资金 1 亿 元，重新规划改造下司古镇。为将下 司古镇打造成著名的风景旅途胜地, 公司用 35000 万竞拍获得下司古镇景 区特许经营权，共 30 年经营期，资金 主要依赖银行贷款, 另外政府正计划 划拨土地给清江旅游开发有限公司作 为补助。据统计, 2016 年有近 120 万 人入景区游玩, 旅游景区收入超过 2.1 亿, 今年上半年接待游客近 82 万人 次, 已经实现实收入 1.85 亿。

特许经营是指特许人拥有或有权 授予他人使用的注册商标、企业标 志、专利、专有技术等经营资源的权
利。特许经营具体有两种类型, 一是 以销售私人产品或服务的方式。例如 两个企业之间达成特许经营的协议, 即特许人生产或制造某种待售产品或 服务, 被许人在固定的区域出售这类 服务或产品, 而被许人需要向其支付 一定的费用。另一种特许经营是提供 公共产品或服务。此种特许是政府及 公共部门将公共产品或者服务的供给 权通过一种特定程序赋予市场主体, 是公私合作制的一种模式, 简称 PPP 特许经营。而运用在特色小镇中的特 许经营是第二种, 运用 PPP 特许经营 的融资模式较为广泛, 政府颁发给企 业特许经营许可证, 赋予企业在一定 范围内经营管理。特许经营在项目开 发运作及融资使用非常有效, 目前国 内使用较多, 对于我国进一步深化改 革、创新融资模式、提升大众服务效 率等方面都有重要价值。特许经营有 多种形式，如 BOT、BT 等，下司古镇 使用的是 BOT 模式, 也即指私营企业 获得各个部门授予一定期限的专营 权, 许可清江旅游开发有限公司融资 建设和经营下司古镇基础设施, 在 30 年特许经营期限中, 清江旅游开发有 限公司通过向游客及景区商家等使用 者收取一定的费用, 从而产生项目收 益。

政府赋予的许可和支持是特许经 营模式的最大特点, 政府可能会为其 提供土地等方面的优惠政策, 被特许 公司可获得更多的融资来源; 此外运 用该模式政府可将借债压力转移至私 营企业, 政府承担的风险将下降, 政 府债务将 “瘦身” ，并可将财政预算 至提高民生的其他领域; 另外有部分 项目将吸引外国有实力的公司来投 资, 将进一步提供的我国在基础设施 领域建设的效率, 并且缓解我国部分 地区资金短缺的问题; BOT 项目通过 社会资本运营管理, 地方政府可学习 借鉴其成功经验, 加快政府运行效 
率。当然 BOT 模式也存在不足之处, 比如在清江旅游开发有限公司的特许 权期限内, 下司古镇项目的所有权和 经营权将不再归政府所有; 另外参与 方可能较多, 组织结构等变得更复 杂; 可能造成设施的掠夺性经营等。

\section{4.特色小镇建设 PPP 融资模式优势分 析}

建设期长、资金投入高是特色小 镇的最大特点, 项目前期可以进行抵 押贷款的资产较少，因此特色小镇的 开发建设资金来源问题是最需解决 的，必须找到一种适宜项目的融资方 式, 进而保障项目顺利进行。当前特 色小镇融资的模式主要有 PPP 融资、 基金 管理、股权众筹资产证券化、供 应链金融等十种模式。在政府的大力 推动使用 PPP 融资模式下, 目前已经 有较多的小城镇使用该模式, 如海宁 皮革时尚小镇、油岭生态旅游小镇、 合肥 “ $P P P+V R+$ 特色小镇” 等。 PPP 模式是通过引进社会资本进入到地方 基础设施等领域建设, 可以有效的减 轻地方政府债务, 解决资金以及能力 不足等方面以进行资源的高效整合, 进而支持特色小镇长期持续的发展建 设。在具体实施中, 政府和企业签订 协议, 按比例组建特色小镇开发有限 公司 (SPV), 以保障特殊小镇顺利建 设。

特色小镇建设的重点是获得持续 稳定的资金支持, 开发特色小镇涉及 到多项的基础设施建设, 因此需要大 量的资金, 而对于贵州大多数市县来 说，仅依靠当地政府财政支持小城镇 的开发建设很难实现。因此, 必须找 到一种合适的融资模式以提供资金支 持, 才能为特色小镇建设保驾护航。 目前特色小镇使用 PPP 模式无疑是最 合适的, 特色小镇在建设中采用的 PPP 融资模式是由政府单方或联合银
行等大型金融机构出资建立引导基 金，而后由社会资本来参与子基金的 设立并针对特定领域或特定项目进行 投资。PPP 模式具体是指政府与私人 组织基于某个项目而形成的相互间合 作关系的一种特许经营项目融资模 式, 由该项目公司负责筹资、建设与 经营。提供贷款的金融机构同公共部 门签订协议, 即公共部门对该机构做 出某种承诺, 未来会依据公共部门和 项目公司签订的合同提供个协议使 SPV 能较顺利地获得金融机构的贷 款。项目的预期收益、资产以及政府 的扶持力度将直接影响贷款的数量和 形式。采取这种融资形式的实质是, 政府通过给予民营企业长期的特许经 营权和权益来加快基础设施的建设及 有效运营。

2016 年 10 月 《国家发展改革委关 于加快美丽特色小（城）镇建设的指 导意见》明确指出: “创新特色小 (城) 镇建设投融资机制, 大力推进 政府和社会资本合作，鼓励利用财政 资金撞动社会资金，共同发起设立美 丽特色小（城）镇建设基金。”各省 份也相继出台政府文件以促进 PPP 模 式运用在特色小镇建设开发上。目 前, 政府正大力推广使用 PPP 模式, 引进社会资本进入基础设施领域建 设, 中央及地方都出台相关政策促进 项目落地, 可以预见未来我国将有更 多的特色小镇选择该模式融资。

\section{5. 特色小镇 PPP 融资模式存在的问题 分析}

当前 PPP 模式在基础设施等领域 使用较为火热, 有部分特色小镇开发 建设亦成果斐然, 如华夏幸福以 “PPP 市场化运作” 为机制, 依托产业集群 的优势, 企业通过提供全产业链服务 的方式, 和政府合作建设开发新型的 特色小镇, 但是就整体情况看, 社会 
资本在进入特色小镇项目时仍如履薄 冰。首先, 特色小镇同质化严重, 部 分地方政府为建特色小镇而建, 没有 特色产业做依托。当前国内已公布建 设的 500 多个小镇来, 传统产业 (旅 游、文化、农林牧渔) 升级领域的小 城镇占比超 $60 \%$, 其中有 $37 \%$ 的小城 镇是以旅游为产业主导, 文化产业小 城镇虽只有 $16 \%$, 但二者的特色小镇 占总量的一半, 所以在第二批特色小 镇申报前, 政府就该项做出限制, 公 布的旅游发展型产业主导的小镇控制 在了三分之一内。在打造特色小镇项 目时,特色产业是其灵魂, 部分特色小 镇仅仅对国内外成功的特色小镇进行 复制, 或打造一个旅游景点作为一个 特色小镇来开发建设。其次, 特色小 镇项目评估困难, 收益难确定, 加大 社会资本进入。民族特色小镇多做为 旅游景区打造, 其大部分收入依赖于 未来的游客量的门票等, 具有较大的 不确定性。另外, 目前国家关于 PPP 方面尚未立法, 法律法规不全, 大多 数都是政府的承诺函或指导性文件, 政府推动, 因此申报的项目多, 但是 落实少, 而且有个别项目完成后, 公 共部门未能照合同完成支付。

目前 PPP 融资模式在社会中有较 大的吸引力, 但存在的部分问题阻碍 社会资本进入, 加之特色小镇建设还 处于发展阶段, PPP 与特色小镇的结 合时间尚短, 且 PPP 融资模式的应用 是一项比较复杂系统工程, 它涉及到 金融、财务、法律和公共管理等多个 领域的问题, 目前并没有某一个特色 小镇可完全参照, 因此特色小镇项目 在融资建设的时候需要政府积极引 导, 加快社会资本进入, 提升贵州城 镇化率, 改善民生, 促进经济持续健 康发展。

\section{6.结语}

培育建设特色小镇对我国当前经 济、民生等方面都有非常大的益处， 特色小镇是我国城镇化发展战略和产 业升级新形态, 实施成功对于经济和 社会发展具有很大的促进。特色小镇 建设需要大量的资金支持, 需要金融 的强力支撑, 资金短缺将制约特色小 镇的发展, 若仅依靠政府融资或国家 政策支持难以支撑特色小镇建设, 因 此需要更高效的融资模式, 以解决特 色小镇资金问题。在特色小镇融资模 式的选择中充分运用 PPP 模式, 能够 有效解决政府单独投资的效率低下问 题、缓解特色小镇建设资金紧缺的矛 盾, 于此同时, 还能够保证在 PPP 模 式选择下各方的利益, 实现共赢的格 局。对于社会资本来说, 可以充分保 障资金的安全性, 又可以保证稳定的 投资的高回报; 对于公共部门, 既可 以减轻政府债务负担, 又能促进当地 经济发展。本课题的研究将对如何解 决特色小镇项目的资金短缺问题、提 高建设及运营效率, 从而促进特色小 镇的可持续发展, 具有较为重要的理 论和实践指导意义。

\section{参考文献}

[1] 李冰,博山特色小镇建设的 PPP 模 式研究, 淄博师专学报, 01:68$74,2017$.

[2] 卫龙宝, 史新杰, 浙江特色小镇建设 的若干思考与建议,浙江社会科 学, 03:28-32,2016.

[3] 刘薇 PPP 模式理论阐释及其现实例 证,改革, 01:78-79,2015.

[4] Paul H.Rubin,"The Theory of the Firm and the Structure of the Franchise Contract",Journal of Law \&

Economics,Vo.21,Iss.1(1978),p.224.

[5] 叶晓毝, 徐春梅. 我国公共项目公私 合作(PPP)模式研究述评, 软科学, 重庆,2013 年. 